\title{
Chlorine and Fluorine Determination in Eye-Pencil: Development of an Eco-Friendly Sample Preparation Method for Ion Chromatography Analysis
}

\author{
Marcia F. Mesko, ${ }^{\oplus *, a}$ Vanize C. Costa, ${ }^{a}$ Rodrigo M. Pereira ${ }^{\circledR a}$ and Carla A. Hartwig ${ }^{a}$ \\ ${ }^{a}$ Centro de Ciências Químicas, Farmacêuticas e de Alimentos, Universidade Federal de Pelotas, \\ 96160-000 Capão do Leão-RS, Brazil
}

\begin{abstract}
In this paper, a feasible method was proposed for the chlorine and fluorine determination in eye-pencil samples using ion chromatography (IC). The microwave-induced combustion (MIC) was used to digest up to $200 \mathrm{mg}$ of a sample, with $50 \mathrm{mg}$ of microcrystalline cellulose as a combustion aid and only water for analytes absorption. $\mathrm{Cl}$ and $\mathrm{F}$ recoveries were $105 \pm 1$ and $93 \pm 5 \%$, respectively, when standard solutions were used in the recovery tests. Certified reference materials (CRM) were also digested mixed to the sample, and no significant difference between the obtained results and the certified values was observed. Precision was assessed in terms of repeatability and intermediate precision, with relative standard deviations (RSD) lower than 9\%. Limits of detection (LOD) for $\mathrm{Cl}$ and $\mathrm{F}$ were 37 and $4 \mathrm{mg} \mathrm{kg}^{-1}$, respectively. Ultrasound-assisted extraction (UEA) was also evaluated; however, the results were not satisfactory. The proposed method was suitable for $\mathrm{Cl}$ and $\mathrm{F}$ determination in eye-pencil because it proved to be accurate, precise and safe, and also minimized waste generation and had high throughput.
\end{abstract}

Keywords: eye-pencil, allergens, microwave-induced combustion, halogen determination, ion chromatography

\section{Introduction}

The area surrounding the eyes is susceptible to irritation and allergic dermatitis because the skin in that area is thin and sensitive. ${ }^{1-3}$ In view of this, cosmetic products can cause adverse effects on the ocular surface, ranging from mild discomfort to vision-threatening conditions. ${ }^{4}$ Therefore, common allergens and irritants such as chlorine and fluorine must be eliminated or at least reduced from the formulations of eye cosmetics. ${ }^{5}$ Although no limit for the $\mathrm{Cl}$ and $\mathrm{F}$ concentrations in eye cosmetics has been established, the Agency for Toxic Substances and Disease Registry (ATSDR) stated that the exposure to these elements can cause irritation and inflammation in the eye area. ${ }^{6}$ Thus, the $\mathrm{Cl}$ and $\mathrm{F}$ determination in cosmetics, such as eye-pencils, is an important task.

Of the cosmetics that are applied to the eyelid region, the eye-pencil is the most used largely due to its ease of application. Eye-pencils are typically composed of waxes (natural or synthetic), oils, pigments and lanolin derivatives, being formed into a rod and placed in a wood casing., 50 the best of our knowledge, only one prior study has involved the halogen determination in this type of eye cosmetic.

*e-mail: marcia.mesko@pq.cnpq.br
This lack of research is probably due to the complexity of the eye-pencil matrix and to the challenges related to the halogen determination such as $\mathrm{Cl}$ and $\mathrm{F}$, as these elements can be converted into volatile species when acids are used for sample preparation. ${ }^{8}$ Moreover, in the one study on this topic in the literature, the researchers only determined fluorine in eye-pencil samples; this study used the combustion ion chromatograph (IC) system. ${ }^{9}$ The limit of detection (LOD) reported by the authors was relatively high, so that method is difficult to apply to a wide variety of samples. ${ }^{9}$ This also emphasizes the need for more suitable methods for determining the halogen level in eye-pencil samples.

Most of the techniques that are used for halogen determination in various matrices require sample solutions for analysis. Such solutions should contain the analytes but should also be free from interfering species; this can usually be achieved through the use of a suitable sample preparation method. ${ }^{10-12}$ The use of acids is not recommended when preparing samples for the halogen determination, so the use of alkaline reagents ${ }^{13}$ and the application of combustion techniques, such as microwaveinduced combustion (MIC), ${ }^{14,15}$ offer promising alternatives for sample preparation prior to the $\mathrm{Cl}$ and $\mathrm{F}$ determination.

MIC has been successfully applied to the food digestion, biological samples, among other organic samples, for 
the subsequent halogen determination, as well as to volatilize the halogens from their inorganic matrices using combustion aids, such as microcrystalline cellulose. ${ }^{14,16}$ In MIC, the sample combustion occurs in closed quartz vessels, which can be pressurized with high-pressure oxygen, thus allowing the digestion of relatively high sample masses. During the combustion reaction, the organic matrix is converted into their oxidation products (mainly, $\mathrm{CO}_{2}$ and $\mathrm{H}_{2} \mathrm{O}$ ), and the analytes are commonly absorbed into diluted alkaline solutions or even into water. ${ }^{14}$

The use of diluted solutions for analyte absorption can prevent the incompatibility of resultant solutions with determination techniques, thus allowing the use of certain techniques, such as potentiometry with ion-selective electrodes and IC, ${ }^{17}$ whose acquisition and maintenance costs are lower than those of atomic spectrometric techniques. ${ }^{18}$ Moreover, $\mathrm{Cl}$ and $\mathrm{F}$ are difficult to determine using atomic spectrometric techniques as these analytes have high ionization potentials and low wavelength emissions. Some important characteristics of IC include multielement detection capability and suitable values of LOD for the $\mathrm{Cl}$ and $\mathrm{F}$ determination. Thus, IC has been widely used for the determination of these elements in several matrices. ${ }^{11,19}$ However, for solid samples, a suitable sample preparation method is essential to obtain a compatible solution to the determination technique.

In view of the importance of the $\mathrm{Cl}$ and $\mathrm{F}$ determination in eye cosmetics, as well as the lack of methods for this purpose and the complexity of the eye-pencil matrix, in this study, a method for determining $\mathrm{Cl}$ and $\mathrm{F}$ in eyepencil using IC is proposed. MIC was used for the sample preparation and, for this, parameters such as the mass of the sample, the use of combustion aids, and the type and concentration of the absorbing solution were carefully evaluated. Additionally, the ultrasound-assisted extraction (UAE) using water or alkaline reagents to extract the analytes from eye-pencil samples was performed before conducting the IC analysis. Recovery tests using standard solutions, as well as the digestion of certified reference materials (CRMs) mixed to the sample, were used to evaluate the accuracy of the proposed method.

\section{Experimental}

\section{Instrumentation}

Eye-pencil samples were manually homogenized under heating at $70{ }^{\circ} \mathrm{C}$ for $20 \mathrm{~min}$ with the aid of a heating plate (RH Basic 2, IKA, China). All weightings were performed on an analytical balance (model AY220, Marte, Brazil) with a resolution of $0.0001 \mathrm{~g}$ and maximum load of $220 \mathrm{~g}$.
A microwave oven system (Multiwave 3000 microwave sample preparation system, Anton Paar, Austria) equipped with eight high-pressure quartz vessels (internal volume of $80 \mathrm{~mL}$ ) was used for sample preparation by MIC. The maximum operational temperature and pressure were set at $280{ }^{\circ} \mathrm{C}$ and 80 bar, respectively. A quartz device was also used inside the vessels as a support for the samples, as proposed by Mesko et al. ${ }^{20}$

Extraction procedures, as well as the decontamination of the wraps (polyethylene films) and combustion aids (cellulose microcrystalline and filter paper discs) used in the MIC procedure, were performed in an ultrasound bath (USC-1800 A, Unique, $40 \mathrm{kHz}, 155 \mathrm{~W}$, Brazil). After the decontamination process, the materials and combustion aids were dried in a class 100 laminar flow-bench (CSLH-12, Veco, Brazil).

Chlorine and fluorine were determined as chloride $\left(\mathrm{Cl}^{-}\right)$ and fluoride $\left(\mathrm{F}^{-}\right)$, respectively, using an ion chromatography with a conductivity detector and a chemical suppressor module (861 advanced compact IC, Metrohm, Switzerland). Detailed information about the operational parameters used for $\mathrm{Cl}$ and $\mathrm{F}$ determination by IC are shown in the "Determination of chlorine and fluorine by IC" section.

\section{Reagents and samples}

Ultrapure water $(18 \mathrm{M} \Omega \mathrm{cm})$ obtained using a purification system (Mega Up, Megapurity, South Korea) was used to prepare solutions, to dilute samples, and to clean materials. Moreover, all reagents used were of analytical grade.

Ammonium carbonate solutions were evaluated as absorbing or extracting solutions in the MIC and UAE procedures, and they were prepared by dissolution of solid reagent (Vetec, Brazil) in water. Tetramethylammonium hydroxide (TMAH) aqueous solutions were prepared from 25\% TMAH in methanol (Sigma-Aldrich, USA), being also evaluated as extracting solutions in the UAE procedure.

For the sample preparation by MIC, an ammonium nitrate solution $\left(6 \mathrm{~mol} \mathrm{~L}^{-1}\right)$ was used as the combustion igniter, which was prepared by dissolution of solid reagent (Merck, Germany) in water. This solution was selected as igniter solution since that presents the better performance on the microwave-induced combustion ignition, according to some studies. ${ }^{21}$ In addition, oxygen with purity of 99.5\% (Linde, Brazil) was used to pressurize the vessels. Pharmaceutical grade microcrystalline cellulose and small discs of filter paper (15 mm of diameter, $12 \mathrm{mg}$ ) with low ash content $(0.5 \%$ ash content, Qualy, J Prolab, Brazil) were used as combustion aids. Nitric acid (Vetec, Brazil) and ethanol (Vetec, Brazil) were used to vessels 
decontamination of the sample preparation system, wraps, combustion aid and other materials used in this study. More details about decontamination processes are shown in the "Cleaning procedures and waste treatment" section.

A solution containing $3.2 \mathrm{mmol} \mathrm{L}^{-1} \mathrm{Na}_{2} \mathrm{CO}_{3}$ and $1.0 \mathrm{mmol} \mathrm{L}^{-1} \mathrm{NaHCO}_{3}$ was used as the mobile phase for $\mathrm{Cl}$ and $\mathrm{F}$ determination by IC. The mobile phase was prepared by dissolution of $\mathrm{Na}_{2} \mathrm{CO}_{3}$ (Synth, Brazil) and $\mathrm{NaHCO}_{3}$ (Merck, Germany) in water. Moreover, $200 \mathrm{mmol} \mathrm{L}^{-1}$ $\mathrm{H}_{2} \mathrm{SO}_{4}$ was prepared from concentrated $\mathrm{H}_{2} \mathrm{SO}_{4}(95-98 \%$, Synth, Brazil), and was used for the regeneration of the suppression system. Reference solutions used in calibration step and recovery tests were prepared by dilution of stock solutions containing $\mathrm{Cl}$ or $\mathrm{F}\left(10000 \mathrm{mg} \mathrm{L}^{-1}\right)$, which were obtained by dissolution of sodium chloride and sodium fluoride salts (Merck, Germany) in water. Certified reference materials (CRMs) of marine sediment (CRM MESS-4, National Research Council Canada, Canada) and coal (CRM BCR 040, European Commission, Belgium) were also used for the accuracy evaluation of the proposed method.

In this study, two brands of eye-pencil (labeled M1 and M2, produced in China and the United States, respectively) in several colors were used (as shown in Table 1). Of these samples, a blue eye-pencil was arbitrarily selected (sample L1) to the method development. Prior to the evaluation of the sample preparation methods, approximately $30 \mathrm{~g}$ of the eye-pencil mixture (waxes, oils and pigments in the form of a rod) were removed from the samples, and this mixture was homogenized using the procedure described in the "Instrumentation" section. After optimizing the proposed method, it was applied for the $\mathrm{Cl}$ and $\mathrm{F}$ determination in the other eye-pencil samples.

Table 1. Identification and general information about the eye-pencil samples used in this study

\begin{tabular}{lccc}
\hline Identification & Color & Brand & Bath \\
\hline L1 & blue & M1 & A05 \\
L2 & grayish brown & M1 & A07 \\
L3 & silver & M1 & B47 \\
L4 & black & M1 & 07100 \\
L5 & white & M2 & V853-W \\
L6 & brown & M2 & V9988-C \\
\hline
\end{tabular}

Microwave-induced combustion (MIC) method

For MIC method, 50 to $250 \mathrm{mg}$ of eye-pencil were mixed with microcrystalline cellulose (0 to $50 \mathrm{mg}$ ) and wrapped by a polyethylene (PE) film $\left(8 \times 8 \mathrm{~cm}^{2}\right)$, which was sealed by heating. Afterward, the PE excess was removed, being that the PE mass used in each wrap was about $30 \mathrm{mg}$.
The PE wraps containing the sample were placed on the base of a quartz holder with a small disc of filter paper. Immediately, $50 \mu \mathrm{L}$ of $6 \mathrm{~mol} \mathrm{~L}^{-1} \mathrm{NH}_{4} \mathrm{NO}_{3}$ were added to the paper, and the quartz holder was introduced into the quartz vessel, containing $6 \mathrm{~mL}$ of absorbing solution (water or $\left(\mathrm{NH}_{4}\right)_{2} \mathrm{CO}_{3}, 50$ or $\left.100 \mathrm{mmol} \mathrm{L} \mathrm{L}^{-1}\right)$. Finally, the vessels were closed, fixed in the rotor, pressurized with 20 bar of oxygen, and subjected to the following microwave heating program: $1400 \mathrm{~W}$ for $5 \mathrm{~min}$, and $0 \mathrm{~W}$ for $20 \mathrm{~min}$.

After the end of the heating program, the pressure of the vessels was released and resultant solutions were diluted with water up to $25 \mathrm{~mL}$ in volumetric flasks for further $\mathrm{Cl}$ and $\mathrm{F}$ determination by IC. The filter paper mass, the oxygen pressure, the heating program, as well as the concentration and the volume of $\mathrm{NH}_{4} \mathrm{NO}_{3}$ used as the combustion igniter, were based on previous studies. ${ }^{20,22}$

\section{Ultrasound-assisted extraction (UAE) method}

UAE was also evaluated for the further $\mathrm{Cl}$ and $\mathrm{F}$ determination in eye-pencil by IC. In the UAE procedure, $500 \mathrm{mg}$ of sample were weighed and transferred together with $6 \mathrm{~mL}$ of extracting solution to polypropylene flasks. Afterward, the flasks were heated at $65^{\circ} \mathrm{C}$ in an ultrasound bath for $90 \mathrm{~min}$ and shaken at intervals of $15 \mathrm{~min}$. This temperature was selected considering that is the maximum temperature of ultrasound bath. In addition, the extraction time was higher than those commonly used in previous works involving UAE to avoid an inefficient extraction. ${ }^{23,24}$ Resultant solutions were filtrated, transferred to volumetric flasks of $25 \mathrm{~mL}$ and the volume completed with water. Water, $100 \mathrm{mmol} \mathrm{L}^{-1}\left(\mathrm{NH}_{4}\right)_{2} \mathrm{CO}_{3}$ and $200 \mathrm{mmol} \mathrm{L}^{-1} \mathrm{TMAH}$ were evaluated as extracting solutions and the use of these solutions was also based on previous studies. ${ }^{13,24}$

\section{Accuracy evaluation}

The accuracy of the proposed method was evaluated by recovery tests, which were performed by addition of $50 \mu \mathrm{L}$ of a standard solution containing $\mathrm{Cl}\left(1500 \mathrm{mg} \mathrm{L}^{-1}\right)$ and $\mathrm{F}\left(360 \mathrm{mg} \mathrm{L}^{-1}\right)$ to the sample (200 $\mathrm{mg}$ of sample plus $50 \mathrm{mg}$ of microcrystalline cellulose) previously to MIC. Moreover, as there is no CRM of eye-pencil, an additional study was performed in order to evaluate the accuracy of the proposed method. In this study, mixtures containing $50 \mathrm{mg}$ of the CRM MESS-4 and $150 \mathrm{mg}$ of sample or $100 \mathrm{mg}$ of the CRM BCR 040 and $100 \mathrm{mg}$ of sample were prepared by MIC, using the optimized conditions. The CRM MESS-4 was used in the recovery tests carried out for the $\mathrm{Cl}$, while the CRM BCR 040 was used in the recovery tests performed for the $\mathrm{F}$. 


\section{Determination of chlorine and fluorine by IC}

As previously mentioned, after sample preparation by MIC or UAE, the $\mathrm{Cl}$ and $\mathrm{F}$ determination was carried out by IC. The operational parameters used for $\mathrm{Cl}$ and $\mathrm{F}$ determination were based on manufacturer's recommendation and previous studies, and they are shown in Table 2. ${ }^{17,25}$

Table 2. Operational parameters used for the $\mathrm{Cl}$ and $\mathrm{F}$ determination by ion chromatography (IC)

\begin{tabular}{|c|c|}
\hline Parameter & Condition \\
\hline Column & $\begin{array}{l}\text { anion-exchange, Metrosep A } \\
\text { Supp } 5 \text { (polyvinylalcohol with } \\
\text { quaternary ammonium groups, } \\
\quad 250 \times 4 \text { mm i.d.) }\end{array}$ \\
\hline Guard column & $\begin{array}{l}\text { Metrosep A Supp } 4 / 5 \text { Guard } \\
\text { (polyvinylalcohol with quaternary } \\
\text { ammonium groups, } 5 \times 4 \mathrm{~mm} \text { i.d.) }\end{array}$ \\
\hline Eluent & $\begin{array}{c}3.2 \mathrm{mmol} \mathrm{L}^{-1} \mathrm{Na}_{2} \mathrm{CO}_{3}+ \\
1.0 \mathrm{mmol} \mathrm{L}^{-1} \mathrm{NaHCO}_{3}\end{array}$ \\
\hline Eluent flow rate $/\left(\mathrm{mL} \mathrm{min}^{-1}\right)$ & 0.7 \\
\hline Injection volume / $\mu \mathrm{L}$ & 20 \\
\hline Determination mode & peak-area \\
\hline
\end{tabular}

For $\mathrm{Cl}$ and $\mathrm{F}$ determination by $\mathrm{IC}$, five calibration standard solutions $\left(0.10\right.$ to $\left.10.0 \mathrm{mg} \mathrm{L}^{-1}\right)$ were prepared by dilution of stock solutions containing the analytes. Depending on the absorbing or extracting solution used for the sample preparation, stock solutions were diluted in water, $10 \mathrm{mmol} \mathrm{L}^{-1}\left(\mathrm{NH}_{4}\right)_{2} \mathrm{CO}_{3}$ or $40 \mathrm{mmol} \mathrm{L}-1$ TMAH.

The GraphPad InStat ${ }^{26}$ software was used for the statistical evaluation of the results. The one-way analysis of variance (ANOVA) followed by the Tukey's test or only by the Student's $t$-test was used to perform the statistical analysis with a confidence level of $95 \%(p \leq 0.05)$.

\section{Cleaning procedures and waste treatment}

Laboratory glassware and other common laboratory materials were decontaminated by immersion in $10 \%(\mathrm{v} / \mathrm{v}) \mathrm{HNO}_{3}$ for at least $24 \mathrm{~h}$, washed with ethanol and water and, posteriorly, dried in a laminar flow-bench. The microcrystalline cellulose and the filter paper discs were used as combustion aids, as well as the PE films were similarly decontaminated. These materials were decontaminated with $10 \%(\mathrm{v} / \mathrm{v}) \mathrm{HNO}_{3}$ for $20 \mathrm{~min}$ in an ultrasound bath. Afterward, the same procedure was performed using ethanol instead of $\mathrm{HNO}_{3}$, the materials were washed with water and dried in a laminar flow-bench.
Quartz vessels and holders used in the MIC procedure were decontaminated using $6 \mathrm{~mL}$ of concentrated $\mathrm{HNO}_{3}$ under heating in the same microwave oven used in the sample preparation. The heating program was as follows: (i) $1400 \mathrm{~W}$ for $10 \mathrm{~min}$, and (ii) $0 \mathrm{~W}$ for $20 \mathrm{~min}$ (cooling step). This procedure was repeated using water instead of $\mathrm{HNO}_{3}$ because this additional step contributes to obtain low blank values for halogens. ${ }^{17}$

The same concentrated $\mathrm{HNO}_{3}$ was used at least twice to decontaminate the quartz vessels and holders. Moreover, the generated waste was separated according its class and neutralized (if necessary) before sending it to the Federal University of Pelotas waste-collection point, where a wastetreatment company picked it up.

\section{Results and Discussion}

Preliminary studies of digestion using microwave-induced combustion

MIC was evaluated for the preparation of the eye-pencil sample due to its suitability for the preparation of organic and inorganic samples prior to the halogen determination. ${ }^{14}$ Initially, a suitable way to insert the eye-pencil sample into the combustion system was evaluated since this type of sample usually adheres easily to the materials that are used to manipulate it. Thus, the samples were wrapped with PE film before introducing them into the combustion system. It was done based on previous study, ${ }^{27}$ in which this material was used to wrap viscous samples.

After choosing the most suitable way to introduce the sample into the combustion system, the maximum sample mass that could be digested by MIC was evaluated. The initial sample mass was $50 \mathrm{mg}$, and it was increased by $50 \mathrm{mg}$ in each subsequent experiment; the presence of soot inside the digestion vessels was observed when $150 \mathrm{mg}$ of eye-pencil or higher masses were used. In this case, the formation of soot is related to the characteristics of the organic compounds from the sample matrix; these compounds projected the sample as it burned, resulting in incomplete combustion. Therefore, to ensure that a higher mass of the eye-pencil sample could be digested, microcrystalline cellulose was evaluated as a combustion aid. This combustion aid was chosen according to a previous study, in which it was used to avoid the projection of honey samples during the combustion process. ${ }^{27}$

With the addition of $50 \mathrm{mg}$ of microcrystalline cellulose, it was possible to digest up to $200 \mathrm{mg}$ of eye-pencil. Sample masses higher than $200 \mathrm{mg}$ were not evaluated because the flames generated during the combustion of the eye-pencil samples were very intense and could have damage the 
PTFE cap of combustion vessels. Figure 1 shows the appearance of the digested samples after combustion (Figure 1a) and the inorganic residues that remained in the quartz holders (Figure 1b). As previously published by our research group, ${ }^{17} \mathrm{Cl}$ and $\mathrm{F}$ can be volatilized from the inorganic matrix in view of their characteristics and higher temperature achieved during the combustion, which separates the residue from the solution, thus preventing interference during the IC analysis.
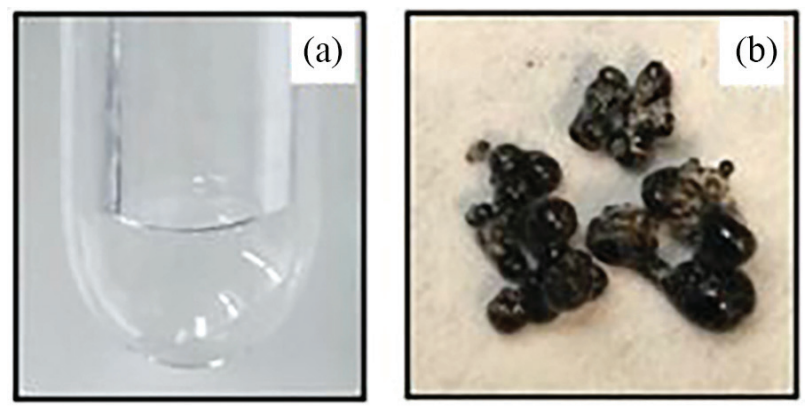

Figure 1. Appearance of (a) solution and (b) inorganic residues obtained after digestion of $200 \mathrm{mg}$ of eye-pencil (sample L1) mixed with $50 \mathrm{mg}$ of microcrystalline cellulose (combustion aid) by microwave-induced combustion (MIC).

Influence of absorbing solution on $\mathrm{Cl}$ and $\mathrm{F}$ recoveries after eye-pencil digestion by MIC

To select the most suitable solution for the $\mathrm{Cl}$ and $\mathrm{F}$ absorption during the digestion of eye-pencil samples using MIC, water and $\left(\mathrm{NH}_{4}\right)_{2} \mathrm{CO}_{3}$ solutions ( 50 or $100 \mathrm{mmol} \mathrm{L}^{-1}$ ) were evaluated. These solutions were chosen since the use of water and alkaline solutions has been used for the absorption of halogens after sample digestion by MIC. ${ }^{17,28}$ Chlorine and fluorine concentrations obtained with IC for each of the evaluated absorbing solutions after the digestion of the eye-pencil samples ( $200 \mathrm{mg}$ of sample plus $50 \mathrm{mg}$ of microcrystalline cellulose) with MIC are shown in Figure 2.

As can be seen in Figure 2, there are no significant differences (ANOVA/Tukey's test, confidence level of 95\%) among the results obtained for $\mathrm{Cl}$ and $\mathrm{F}$, regardless of whether water or one of the $\left(\mathrm{NH}_{4}\right)_{2} \mathrm{CO}_{3}$ solutions (50 or $100 \mathrm{mmol} \mathrm{L}^{-1}$ ) was used for analytes absorption. Thus, water was chosen for the subsequent studies as it is the most compatible with the determination technique and leads to the least waste generation.

Figure 3 presents chromatograms obtained after the analysis of a standard solution used in the calibration step, as compared to that of the solution obtained after the digestion of the eye-pencil sample using MIC, with water as the absorbing solution. The chromatogram from the sample analysis (red line in Figure 3) indicates that MIC is a suitable sample preparation method for the subsequent

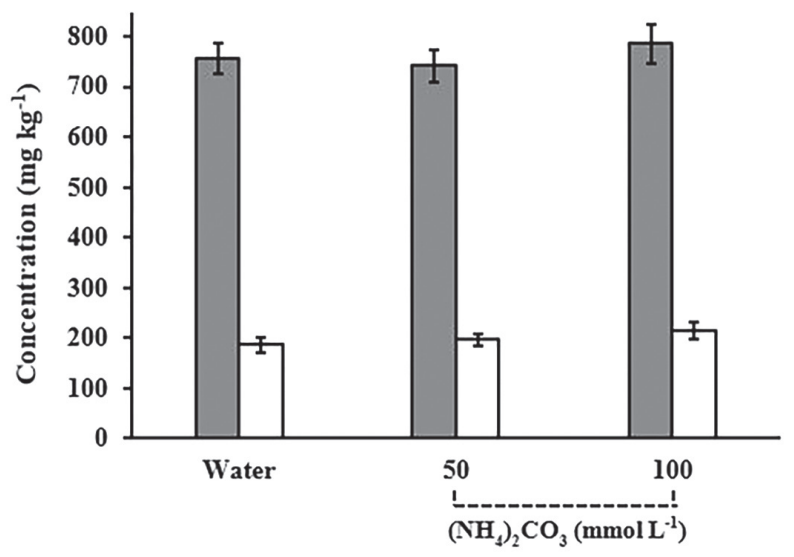

Absorbing solution

Figure 2. Concentrations of $\mathrm{Cl} \square$ and $\mathrm{F} \square$ obtained by ion chromatography (IC) after eye-pencil digestion by microwave-induced combustion (MIC) using water or $\left(\mathrm{NH}_{4}\right)_{2} \mathrm{CO}_{3}$ solutions (50 or $100 \mathrm{mmol} \mathrm{L}^{-1}$ ) to absorb the analytes $(n=3)$.

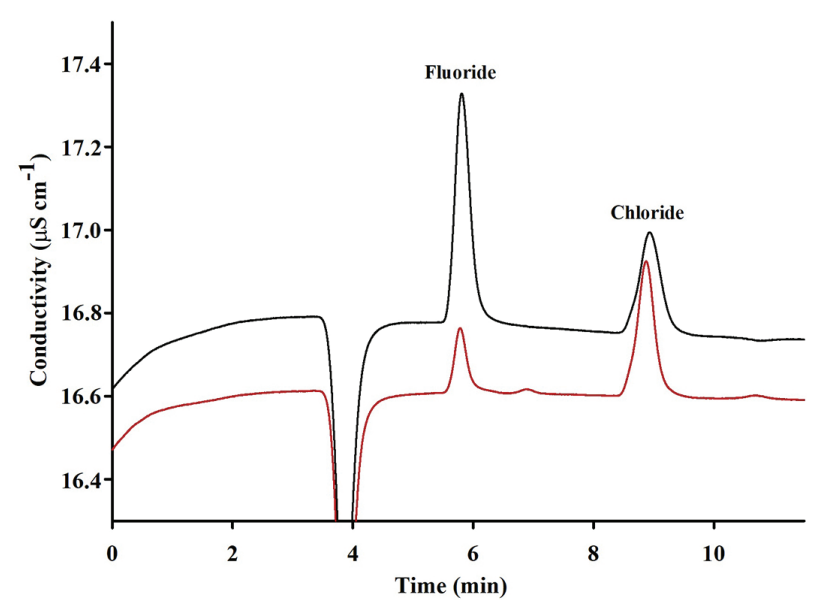

Figure 3. Chromatogram obtained after the analysis of a standard solution containing $0.5 \mathrm{mg} \mathrm{L}^{-1}$ of F- and $\mathrm{Cl}^{-}(-)$and the eye-pencil digests obtained by microwave-induced combustion (MIC) using water as the absorbing solution (-).

$\mathrm{Cl}$ and $\mathrm{F}$ determination in eye-pencil by $\mathrm{IC}$, as this method provides baseline stability during the analysis and produces an appropriate chromatographic resolution of the peaks (around 2.5).

\section{Accuracy and precision evaluations}

To evaluate the accuracy of the proposed method, recovery tests were performed adding standard solutions to the samples, as mentioned previously. Recoveries for $\mathrm{Cl}$ and $\mathrm{F}$ were $105 \pm 1$ and $93 \pm 5 \%$, respectively. In addition, CRMs (MESS-4 and BCR 040) were digested mixed to the sample. The CRM MESS-4 was used in the recovery tests performed for the $\mathrm{Cl}$, while the CRM BCR 040 was used in the recovery tests carried out for $\mathrm{F}$, considering the certified values for CRMs. This additional study was performed to 
simulate (as closely as possible) what occurs to the analytes during the digestion of an eye-pencil sample using MIC as no existing CRMs with similar matrix to that of the eye-pencil samples. Moreover, CRMs with high inorganic content were selected because the eye-pencil samples have a significant inorganic content, which could influence in the analytes recoveries since the elements can be linked to the inorganic residues remaining after the combustion process. The masses of recovered $\mathrm{Cl}$ and $\mathrm{F}$ were calculated and related to the masses of CRMs that were mixed to the sample. For this, initially, the $\mathrm{Cl}$ and $\mathrm{F}$ concentrations in the samples were subtracted from the final determined concentrations after mixing an aliquot of the sample with the CRMs. The concentration obtained for $\mathrm{Cl}\left(11146 \pm 368 \mathrm{mg} \mathrm{kg}^{-1}\right)$ and $\mathrm{F}$ $\left(107 \pm 3 \mathrm{mg} \mathrm{kg}^{-1}\right)$ did not differ significantly (Student's $t$-test, confidence level of $95 \%$ ) from the certified concentration for the $\mathrm{Cl}$ in the CRM MESS-4 $\left(13100 \pm 4400 \mathrm{mg} \mathrm{kg}^{-1}\right)$ and for the F in the CRM BCR $040\left(111.4 \pm 7.6 \mathrm{mg} \mathrm{kg}^{-1}\right)$, respectively. In this way, the results for the proposed method showed suitable accuracy in the $\mathrm{Cl}$ and $\mathrm{F}$ determination using IC, and indicating that analytes are not retained in the inorganic residue during the MIC procedure. Moreover, these results indicate that the $\mathrm{Cl}^{-}$and $\mathrm{F}^{-}$determination by $\mathrm{IC}$ can be used to indirectly quantify $\mathrm{Cl}$ and $\mathrm{F}$ in eye-pencil after sample preparation using the MIC method. Using the optimized conditions, low relative standard deviations (RSDs < 9\%) and LODs (Cl: $37 \mathrm{mg} \mathrm{kg}^{-1} ; \mathrm{F}: 4 \mathrm{mg} \mathrm{kg}^{-1}$ ) were obtained. According to the proposed method, the $\mathrm{Cl}$ and $\mathrm{F}$ concentrations in the L1 eye-pencil sample were $758 \pm 36$ and $186 \pm 16 \mathrm{mg} \mathrm{kg}^{-1}$, respectively.

The LOD values were calculated from the mean values, and the standard deviations obtained from the analysis of 10 replicates of the analytical blank, according to Instituto Nacional de Metrologia, Normalização e Qualidade Industrial (INMETRO) and Eurachem guidelines. ${ }^{29,30}$ The sample mass, the final volume of the digests, and, when necessary the dilution factor, were also considered during the calculation of the LOD values.

The throughput of MIC was comparable with that of the method proposed by Schultes et al. ${ }^{9}$ for the F determination in eye-pencil since up to eight samples can be digested in less than $30 \mathrm{~min}$ using MIC. In addition, the MIC method has a relatively high throughput when compared to other methods used for the decomposition of eye-pencil, which involve the use of acids for the sample preparation aiming at the subsequent metal determination. ${ }^{31,32}$ As previously mentioned, the acid digestion methods are not recommended for the subsequent halogen determination, and generally they have a lower decomposition efficiency than MIC, when samples with high lipid contents, such as eye-pencil, are decomposed.

\section{Comparison of UAE to MIC methods}

$\mathrm{UAE}$ was used to the $\mathrm{F}$ and $\mathrm{Cl}$ extraction from the eye-pencil sample and further determination by IC. This method was evaluated because alkaline solutions could also be used for the subsequent halogen determination and because the use of ultrasound could contribute to the extraction process. ${ }^{13}$

Water, $100 \mathrm{mmol} \mathrm{L}^{-1}\left(\mathrm{NH}_{4}\right)_{2} \mathrm{CO}_{3}$ and $200 \mathrm{mmol} \mathrm{L}^{-1}$ TMAH were evaluated as extracting solutions. TMAH was evaluated because it is widely used in sample preparation procedures that involve alkaline extraction or dissolution. ${ }^{13}$ On the other hand, $\left(\mathrm{NH}_{4}\right)_{2} \mathrm{CO}_{3}$ solutions were used due to their efficiency at absorbing halogens during MIC sample preparation. ${ }^{14}$ Solutions obtained after eye-pencil $(500 \mathrm{mg})$ sample preparation by UAE using the evaluated extracting solutions are shown in Figure 4.

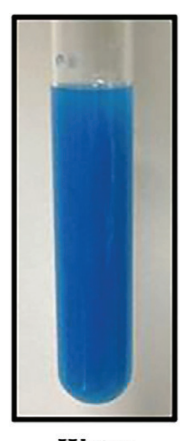

Water

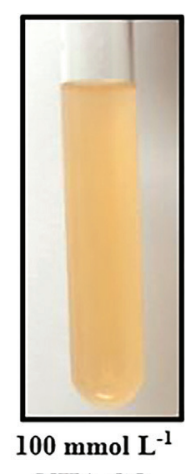

$\left(\mathrm{NH}_{4}\right)_{2} \mathrm{CO}_{3}$

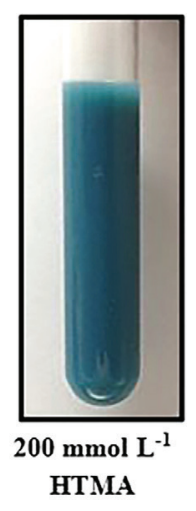

Figure 4. Appearance of the solutions obtained after eye-pencil sample preparation (sample L1) by ultrasound-assisted extraction (UAE) using water, $100 \mathrm{mmol} \mathrm{L}^{-1}\left(\mathrm{NH}_{4}\right)_{2} \mathrm{CO}_{3}$ or $200 \mathrm{mmol} \mathrm{L}^{-1} \mathrm{TMAH}$ as the extracting solutions.

As can be seen in Figure 4, the solutions after UAE presented varied appearance, especially for the $100 \mathrm{mmol} \mathrm{L}^{-1}\left(\mathrm{NH}_{4}\right)_{2} \mathrm{CO}_{3}$ extracting solution. This behavior is likely associated with the aqueous-soluble constituents of the sample, which are chemically modified in the presence of $\left(\mathrm{NH}_{4}\right)_{2} \mathrm{CO}_{3}$. When $200 \mathrm{mmol} \mathrm{L}^{-1} \mathrm{TMAH}$ was used, the resultant solutions had higher turbidity than the others did. As TMAH interacts with apolar substances, its high turbidity is likely related to the extraction of apolar constituents from the sample.

Although TMAH interacted efficiently with the samples, the results for $\mathrm{Cl}$ and $\mathrm{F}$ were lower than the LOD values ( $\mathrm{Cl}: 7488 \mathrm{mg} \mathrm{kg}^{-1}$ and $\mathrm{F}: 3150 \mathrm{mg} \mathrm{kg}^{-1}$ ) of the method. This occurred due to incompatibility between the extract and the determination technique, which requires a high dilution factor (about 300 times) and, consequently, resulting in high LOD values for both analytes. 
Regarding to the results obtained for $\mathrm{Cl}$, it is also important to mention that significant differences (Student's $t$-test, confidence level of 95\%) were verified between the concentrations obtained using water $\left(371 \pm 36 \mathrm{mg} \mathrm{kg}^{-1}\right)$ and those obtained using $100 \mathrm{mmol} \mathrm{L}^{-1}\left(\mathrm{NH}_{4}\right)_{2} \mathrm{CO}_{3}$ $\left(486 \pm 28 \mathrm{mg} \mathrm{kg}^{-1}\right)$ as the extracting solution. Moreover, these results were lower than those obtained after sample preparation by MIC $\left(758 \pm 36 \mathrm{mg} \mathrm{kg}^{-1}\right)$. Thus, the results indicate that $\mathrm{Cl}$ was not quantitatively extracted from the sample using water or $100 \mathrm{mmol} \mathrm{L}^{-1}\left(\mathrm{NH}_{4}\right)_{2} \mathrm{CO}_{3}$. In addition, the $\mathrm{F}$ concentrations obtained using water $\left(70 \pm 2 \mathrm{mg} \mathrm{kg}^{-1}\right)$ or $100 \mathrm{mmol} \mathrm{L}^{-1}\left(\mathrm{NH}_{4}\right)_{2} \mathrm{CO}_{3}$ (lower than $90 \mathrm{mg} \mathrm{kg}^{-1}$ ) as the extracting solution was lower than those obtained after using MIC $\left(186 \pm 16 \mathrm{mg} \mathrm{kg}^{-1}\right)$, indicating that the extraction process was also inefficient for this analyte.

\section{Determination of chlorine and fluorine in eye-pencil}

Based on the results obtained in this study, MIC was selected for the preparation of the eye-pencil samples aiming the $\mathrm{Cl}$ and $\mathrm{F}$ determination using IC. Chlorine and $\mathrm{F}$ concentrations in eye-pencil of several colors (black, blue, brown, grayish brown, silver and white) obtained by IC after sample digestion by MIC (200 mg of sample plus $50 \mathrm{mg}$ of microcrystalline cellulose), using $6 \mathrm{~mL}$ of water to absorb the analytes absorption, are shown in Table 3.

Table 3. Chlorine and fluorine concentrations in eye-pencil of several colors determined by ion chromatography (IC) after sample digestion by microwave-induced combustion (MIC) using water to absorb the analytes (mean \pm standard deviation, $\mathrm{n}=3$ )

\begin{tabular}{lcccc}
\hline \multirow{2}{*}{ Identification } & \multirow{2}{*}{ Brand } & Color & \multicolumn{2}{c}{ Concentration $/\left(\mathrm{mg} \mathrm{kg}^{-1}\right)$} \\
\cline { 3 - 5 } & & & $\mathrm{Cl}$ & $\mathrm{F}$ \\
\hline L1 & M1 & blue & $758 \pm 36$ & $186 \pm 16$ \\
L2 & & grayish brown & $150 \pm 12$ & $327 \pm 21$ \\
L3 & & silver & $<37^{\mathrm{a}}$ & $135 \pm 11$ \\
L4 & & black & $76.1 \pm 6.5$ & $50.7 \pm 0.2$ \\
L5 & M2 & white & $<37^{\mathrm{a}}$ & $12.4 \pm 1.1$ \\
L6 & & brown & $76.9 \pm 5.6$ & $22.3 \pm 1.9$ \\
\hline
\end{tabular}

aOD: limit of detection.

As can be seen in Table 3, in the analyzed samples, the mean concentrations of $\mathrm{Cl}\left(<37\right.$ to $\left.758 \mathrm{mg} \mathrm{kg}^{-1}\right)$ and $\mathrm{F}$ (12.4 to $327 \mathrm{mg} \mathrm{kg}^{-1}$ ) varied in a wide range. Additionally, it was possible to verify that the $\mathrm{F}$ concentration was higher than the $\mathrm{Cl}$ concentration in some samples (specifically, the grayish brown and silver eye-pencils).

The lowest concentrations of both analytes were founded in the white eye-pencil and the highest $\mathrm{Cl}$ and $\mathrm{F}$ concentrations in the blue and grayish brown eye- pencils, respectively. Thus, although the samples differed by bath and/or by brand, the variations in the $\mathrm{Cl}$ and $\mathrm{F}$ concentrations indicate that the presence of these elements in the eye-pencil may be related to the coloring agents used in this type of cosmetic. In view of these variations and the adverse effects that $\mathrm{Cl}$ and $\mathrm{F}$ have on the ocular surface, it is clearly necessary to control the concentration of these elements in eye-pencils. Despite this, only one previous study has involved halogen determination in this type of eye cosmetic. ${ }^{9}$ In addition, no legislation has established a limit for $\mathrm{Cl}$ and $\mathrm{F}$ in eye cosmetics.

\section{Conclusions}

The UAE method for the extraction of the analytes from the eye-pencil samples was not efficient. High LOD values were obtained for some conditions due to the incompatibility of the extracts with the determination techniques, leading to a need for additional dilution prior to analysis. On the other hand, the MIC method was suitable for eye-pencil sample preparation prior to the $\mathrm{Cl}$ and $\mathrm{F}$ determination using IC. This method allowed for the efficient digestion of the samples' organic constituents and promoted the separation of the analytes from the corresponding inorganic fractions (which could interfere with the IC analysis). Moreover, water was suitable for the absorption of the analytes as it is compatible with the determination technique and leads to reduced waste generation. The proposed method (which combines MIC and IC) also had satisfactory accuracy and precision, low values for the blanks and LODs, and relatively high throughput (as up to eight samples can be digested in less than $30 \mathrm{~min}$ and as the chromatographic run can be done in less than $10 \mathrm{~min}$ ).

The $\mathrm{Cl}$ and $\mathrm{F}$ concentrations in the analyzed eye-pencils showed a wide range of variance. Thus, the obtained results confirm the importance of this study and the need for regulatory agencies to establish limits on $\mathrm{Cl}$ and $\mathrm{F}$ in eye-pencils. Such measures could prevent health problems for consumers. In this context, and in view of both the lack of methods in the literature for this purpose and the features of the proposed method, it is possible to affirm that a method involving MIC with IC is promising for the $\mathrm{Cl}$ and $\mathrm{F}$ determination in eye-pencils. This combined method can thus be used in routine analysis.

\section{Acknowledgments}

The authors are grateful to CAPES (finance code 001), CNPq (grant numbers 409357/2016-2 and 309424/2016-0) and FAPERGS (grant number 16/2551-0000561-8) for supporting this study. 


\section{References}

1. Saxena, M.; Warshaw, E.; Ahmed, D. D. F.; Am. J. Contact. Dermat. 2001, 12, 38.

2. Temesvári, E.; Pónyai, G.; Németh, I.; Hidvégi, B.; Sas, A.; Kárpáti, S.; J. Eur. Acad. Dermatol. 2009, 23, 124.

3. Travassos, A. R.; Bruze, M.; Dahlin, J.; Goossens, A.; Contact Dermatitis 2011, 65, 307.

4. Coroneo, M. T.; Rosenberg, M. L.; Cheung, L. M.; Ocul. Surf. 2006, $4,94$.

5. Draelos, Z. D.; Clin. Dermatol. 2001, 19, 424.

6. Agency for Toxic Substances and Disease Registry (ATSDR), http://www.atsdr.cdc.gov, accessed in May 2019.

7. Vickery, S. A.; Kolas, R.; Dicko, F. In Cosmetic Dermatology: Products and Procedures; Draelos, Z. D., ed.; Wiley-Blackwell: New Jersey, USA, 2016, ch. 23.

8. Barnes, R. M.; Júnior, D. S.; Krug, F. J. In Microwave-Assisted Sample Preparation for Trace Element Analysis; Flores, E. M. M., ed.; Elsevier: Amsterdam, Netherlands, 2014, ch. 1.

9. Schultes, L.; Vestergren, R.; Volkova, K.; Westberg, E.; Jacobson, T.; Benskin, J. P.; Environ. Sci. Processes Impacts 2018, 20, 1680.

10. Rocha, F. R. P.; Nóbrega, J. A.; Kamogawa, M. Y. In Métodos de Preparo de Amostras para Análise Elementar; Krug, F. J.; Rocha, F. R. P., eds.; EditSBQ: São Paulo, Brasil, 2016, ch. 2.

11. Mello, P. A.; Barin, J. S.; Duarte, F. A.; Bizzi, C. A.; Diehl, L. O.; Muller, E. I.; Flores, E. M. M.; Anal. Bioanal. Chem. 2013, 405, 7615.

12. Anderson, R.; Sample Pretreatment and Separation; John Wiley \& Sons: London, England, 1987.

13. Nóbrega, J. A.; Santos, M. C.; Sousa, R. A.; Cadore, S.; Barnes, R. M.; Tatro, M.; Spectrochim. Acta, Part B 2006, 61, 465.

14. Barin, J. S.; Flores, E. M. M.; Mesko, M. F.; Mello, P. A.; Pereira, J. S. F. In Microwave-Assisted Sample Preparation for Trace Element Analysis; Flores, E. M. M., eds.; Elsevier: Amsterdam, Netherlands, 2014, ch. 5.

15. Flores, E. M. M.; Barin, J. S.; Mesko, M. F.; Knapp, G.; Spectrochim. Acta, Part B 2007, 62, 1051.

16. Mesko, M. F.; Costa, V. C.; Picoloto, R. S.; Bizzi, C. A.; Mello, P. A.; J. Anal. At. Spectrom. 2016, 31, 1243.

17. Pereira, R. M.; Costa, V. C.; Hartwig, C. A.; Picoloto, R. S.; Flores, E. M. M.; Duarte, F. A.; Mesko, M. F.; Talanta 2016, 147,76 .
18. López-Ruiz, B.; J. Chromatogr. A 2000, 881, 607.

19. Morales-Rubio, Á.; de la Guardia, M. In Handbook of Mineral Elements in Food; de la Guardia, M.; Garrigues, S., eds.; John Wiley \& Sons: New Jersey, USA, 2015, ch. 16.

20. Mesko, M. F.; Moraes, D. P.; Barin, J. S.; Dressler, V. L.; Knapp, G.; Flores, E. M. M.; Microchem. J. 2006, 82, 183.

21. Pereira, L. S. F.; Iop, G. D.; Nascimento, M. S.; Diehl, L. O.; Bizzi, C. A.; Barin, J. S.; Flores, E. M. M.; J. Braz. Chem. Soc. 2016, 27, 526.

22. Flores, E. M. M.; Barin, J. S.; Paniz, J. N. G.; Medeiros, J. A.; Knapp, G.; Anal. Chem. 2004, 76, 3525.

23. Silva, R. G. L.; Santelli, R. E.; Willie, S. N.; Sturgeon, R. E.; Sella, S. M.; Analyst 1999, 124, 1843.

24. Gélinas, Y.; Iyengar, G. V.; Barnes, R. M.; Fresenius J. Anal. Chem. 1998, 362, 483.

25. Eith, C.; Kolb, M.; Seubert, A.; Viehweger, K. H.; Practical Ion Chromatography; Metrohm Ltd.: Herisau, Switzerland, 2001.

26. GraphPad Instat version 3; GraphPad Software Inc; San Diego, CA, USA, 2002.

27. Costa, V. C.; Picoloto, R. S.; Hartwig, C. A.; Mello, P. A.; Flores, E. M. M.; Mesko, M. F.; Anal. Bioanal. Chem. 2015, 407, 7957.

28. Antes, F. G.; Pereira, J. S. F.; Spadoa, L. C.; Muller, E. I.; Flores, E. M. M.; Dressler, V. L.; J. Braz. Chem. Soc. 2012, 23, 1193.

29. Instituto Nacional de Metrologia, Qualidade e Tecnologia (INMETRO); Orientação sobre Validação de Métodos Analíticos DOQ-CGCRE-008, Rio de Janeiro, Brasil, 2018. http://www.inmetro.gov.br/credenciamento/organismos/ doc_organismos.asp?tOrganismo=CalibEnsaios, accessed in May 2019.

30. Eurachem; The Fitness for Purpose of Analytical Methods: A Laboratory Guide to Method Validation and Related Topics; Torino, Italy, 2014, https://www.eurachem.org/index.php/ publications/guides/mv, accessed in May 2019.

31. Iwegbue, C. M. A.; Bassey, F. I.; Obi, G.; Tesi, G. O.; Martincigh, B. S.; Toxicol. Rep. 2016, 3, 464.

32. Igwo-Ezikpe, M.; Olasore, H.; Osuala, F.; Obidi, O.; Ayanshina, O.; Taiwo, F.; Sotinala, O.; Biokemistri 2017, 29, 110.

Submitted: February 1, 2019

Published online: May 24, 2019 